\title{
SIMULATION MODELLING AND ANALYSIS FOR IMPROVING THE PERFORMANCE OF PRODUCTION CASE STUDY: JORDANIAN VEHICLES MANUFACTURING COMPANY
}

\author{
Mohammad D. Al-Tahat \\ Industrial Engineering Department, University of Jordan, Amman 11942 - Jordan, Tel.: +962 6 5355000, Ext. 22933, \\ Fax: +962 65300813 , altahat@ ju.edu.jo (corresponding author) \\ Ammar A. Alrousan \\ Yarmouk University, Industrial Engineering, Hijjawi Faculty of Engineering Technology, Irbid, 21163, Jordan, \\ alrousana@yu.edu.jo \\ Mahmoud Z. Mistarihi \\ Yarmouk University, Industrial Engineering, Hijjawi Faculty of Engineering Technology, Irbid, 21163, Jordan, \\ mahmoud.m@yu.edu.jo \\ Faten Al Shalabi \\ Yarmouk University, Industrial Engineering, Hijjawi Faculty of Engineering Technology, Irbid, 21163, Jordan, \\ Fatenhani95@hotmail.com \\ Sajeda Abu-Bajah \\ Yarmouk University, Industrial Engineering, Hijjawi Faculty of Engineering Technology, Irbid, 21163, Jordan, \\ sajeda.mohammad995@gmail.com
}

Keywords: ARENA Simulation, production modelling, production lines, process utilisation

Abstract: Modelling and analysing production lines are crucial for the research community and designers interested in increasing production utilisation and reducing costs. This paper aims to model and analyse a real production process of a Jordanian vehicles manufacturing company and improve production line resource utilisation using ARENA simulation software. The methodology used is simulation modelling to develop a new production line design. Performance measures are obtained from data given by the company management and direct observation of the production line. A suggested modified Arena simulation model is developed for the production line processes based on the collected data. Verification and validation analysis of the proposed model is done. Results show that the proposed model's performance is better than the current one in terms of; overall total processing time, the overall waiting time, the overall work in process, and the overall utilisation.

\section{Introduction}

Simulation is the imitation of the processes of a realworld system in generating an artificial history to draw inferences concerning the operating characteristics of the real system [1]. Simulation modelling is used to optimise the performance of a real-world system with low cost, secure and fast analysis with many different system configurations [2]. Simulation software programs are used to simulate the process, which brings the power of modelling and simulation to business process improvement. It is considered a powerful tool to help demonstrate, predict, and measure system strategies for effective, efficient, and optimised performance.

Manufacturing provides one of the most important applications of simulation. Especially in studying and analysing the production lines to determine how well production facilities are being used. According to Fauci et al. [3], simulation of production lines is such a powerful tool in obtaining the performance measures in situations where analytical techniques are either difficult or impossible to use.
It is proposed in [4] that, a semantic conceptualisation to describe an organised Sensitive Business Processes within a new Business Process Meta-model for Knowledge Identification (BPM4KI). The proposed model covered all the aspects including the organisational, functional, informational, behavioral, knowledge, and intentional perspectives. The proposed model is semantically rich and well based on «core» domain ontologies.

A decision-making model for applying for the knowledge transfer support effectively in manufacturing enterprises using the GMDH approach is discussed in [5], The model [5] focused on several knowledge workers characteristics within manufacturing companies based on a survey from 119 Polish enterprises.

A process-based knowledge management framework to analyse knowledge flow employing a two-phase analysis: knowledge-flow analysis and process analysis is proposed in [6]. The results showed that the proposed knowledgeflow model was useful in recognising the relationship between the manufacturing processes and knowledge where the diagram acts as a knowledge mediator amongst 
SIMULATION MODELLING AND ANALYSIS FOR IMPROVING THE PERFORMANCE OF PRODUCTION CASE STUDY: JORDANIAN VEHICLES MANUFACTURING COMPANY

Mohammad D. Al-Tahat; Ammar A. Alrousan; Mahmoud Z. Mistarihi; Faten Al Shalabi; Sajeda Abu-Bajah

a worker and the associated successor. Patalas et al. [7] presented the ExKnowIT information system that is supporting the expert knowledge eliciting for successful IT projects. The model consisted of (1) the experts' identification for successful information technology projects, (2) the expert knowledge eliciting on finished IT projects, (3) the expert knowledge according to finished information technology projects, (4) the Group Method for Data Handling (GMDH) algorithm, (5) manager selection new knowledge for a new information technology project.

A model for utilising, managing, and collecting integrated engineering outputs within the life-cycle process of the product is proposed in [8], where the model output acquisition was designed for assembling outputs without further efforts when time outputs were registered, given that with the project schedule. As revision happens within the project period, the revision is transferred to the corresponding process through the Engineering Change Order process. The results showed that the system in the electric transformer EPC project performing usability, concurrent-multiple projects, and an accumulating outputs degree that comprises process accuracy and revision history was enhanced about the PDM (Product Data Management) system used previously.

The purpose of this research study is to apply ARENA software to simulate, evaluate and improve the performance of a production line as a real case study at one Jordanian vehicle manufacturing company. Actual data is collected and analysed for each workstation, including processing time, the overall waiting time, the overall work in process, and the overall utilisation. Arena software is chosen for this study due to its modelling flexibility and ease of use. It provides building models for many scenarios and options to document, visualise, and demonstrate the dynamics of a process with animation. It also predicted system performance based on key metrics such as throughput, cycle times, and utilisations.

Moreover, it identifies process bottlenecks such as queue build-ups and overutilisation of resources [9]. Many scientific papers have shown that simulation is an effective tool that helps solve many industry problems [10]. In this paper, problem description and methodology are introduced in Section 2. The proposed production line model is presented in Section 3. Results and discussion are demonstrated in Section 4. Finally, the conclusion and recommendations are summarised in Section 5.

\section{Problem description and research methodology}

After investigating and analysing the current process flow of the production lines for producing the vehicle, a new production line layout is proposed based on simulation modelling and choosing the appropriate lean manufacturing tools to eliminate the non-added value activities. The production processes consist of 13 workstations that contain many activities starting by preparing the chassis, grinding the Armor, fitting hinges, releasing the door then fitting all brackets and spacers, painting process, preparing the floor, and fitting some electrical and mechanical parts, trimming process plus fitting accessories and finally, painting. To achieve the previous research objective, a compression study between the current process flows versus the future process flow regarding total time, waiting time, several works in process, and resource utilisation. The simulation modelling research methodology is proposed and illustrated in Figure 1. The full current process is shown in Figure 2, where a Value Stream Map (VSM) of the existing production line is built as an experimental model by placing modules that represent processes or logic. The VSM shows how these modules are connected and joined together to specify the flow of entities within the company's production lines [11]. This requires the design and development of a new production line that has improved future productivity of all aspects of vehicle production.

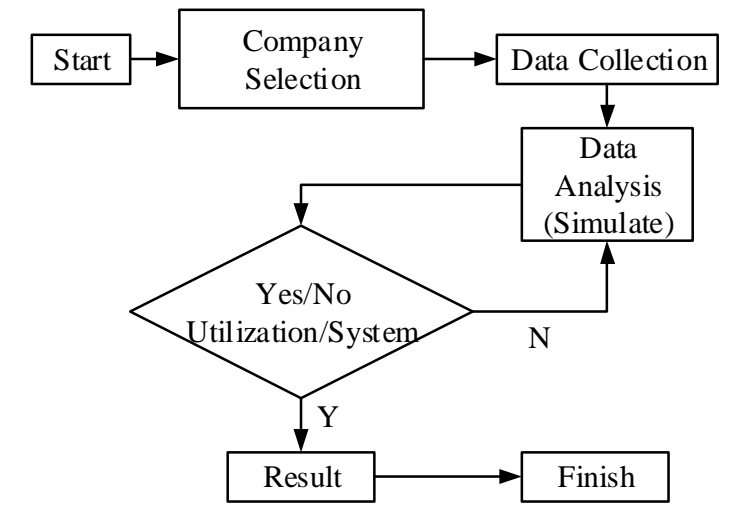

Figure 1 Schematic presentation of the research methodology

\subsection{Company selection}

The considered vehicles manufacturing company is a Jordanian company in partnership with other companies. It was established to develop, manufacture, and market special and protected vehicles worldwide for international governmental and non-governmental organisations. The company is considered a prime pillar in the local automotive and industrial cluster. It is a customer-driven company, where the production strategy followed by the company is "male to order" while ensuring the best operational practices and the highest armouring standards [12]. The vehicles that the company produces are operated in more than 30 countries all over the world. Their vision is to be a world-class manufacturer of light vehicles, and their mission is to manufacture and sell high-quality protected and special purpose light vehicles and their components for the law enforcement, security, and civilian markets worldwide, fulfilling customers' requirements [12]. The facility is located in Jordan, and it encompasses eight production lines, a well-equipped off-line production area, warehouses, and the administration. 


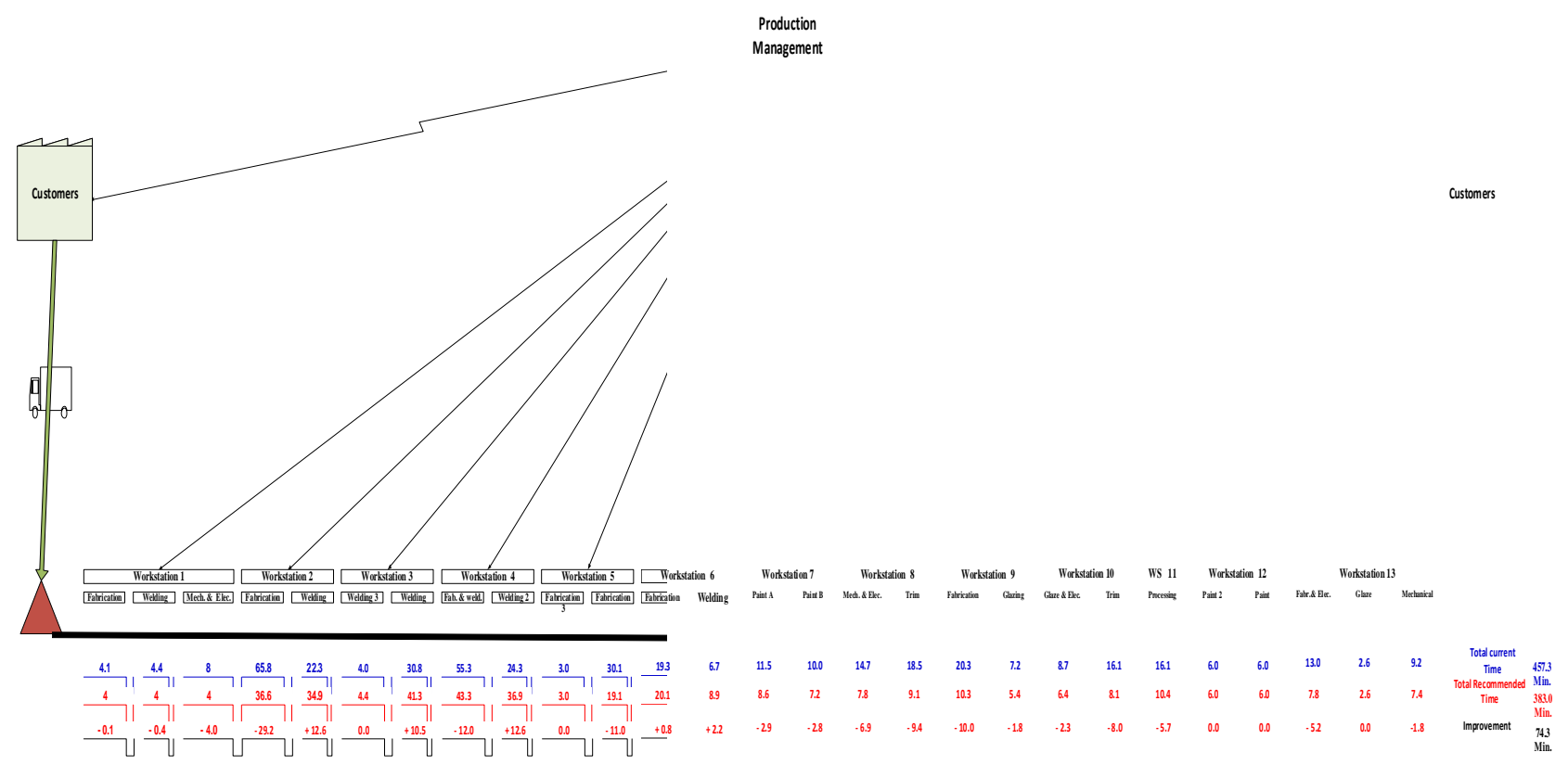

Figure 2 Value Stream Mapping (VSM) of the current production processes for producing the vehicle

\subsection{Data gathering and data modules}

Actual operational data has been collected by visiting the factory several times and observing the production line to understand the interrelations between activities and realise the structural process constraints. Performance measures are obtained from data given by the company management. The collected data is well planned in targeting key data contemplate the simulation model objectives such as total processes time, waiting time, resources utilisation, and the number of process works.

A set of modelling assumptions are set according to the system constraints related to the process type, workforce size, and the entity's movement sequence between the stations. In the current and proposed production line simulation, three data modules are used, the entity data module, which is the vehicle, the resource data module in the simulation system for all workstations. Finally, the station data module defines a set of stations corresponding to a physical or logical location where processing occurs.

\section{Proposed production line model}

According to follow process flowchart within the production workstations, the ARENA flow model was constructed as shown in Figure 3. Sub-model was used to facilitate handling of simulation flow model [13]. A sample for workstation No. 1 in the current model and the proposed model is shown in Figure 4 and Figure 5, respectively. To improve resource utilisation, the current layout of the company's production line has been developed. Figure 6 shows the proposed production line model. It reduces the total processing time and reduces the waiting time, thus making the production line more efficient.

\subsection{Verification and validation}

The verification step consists of verifying that the computer program performs properly. In other words, is the computer program the exact translation of the knowledge model? Usually, with complex systems, it is difficult, if not impossible, to translate a model successfully without a good deal with debugging. During the verification phase of the simulation model following steps have been implemented: check that the computer program does what it is supposed to. Use sound programming techniques. Check the output for reasonableness and view animations [14].

After the verification stage, validation is so important to be sure that the model is an accurate representation of the real system. Validation is usually performing through the calibration of the model. It consists of an iterative process of comparing the model with the system and adjusting parameters. Of course, if the validation fails, the data collected and/or the knowledge model can be reconsidered. Validation steps include: Check that the model accurately reflects the real system. Compare model output to real system output. Involve system experts and model users throughout development and explicitly state and verify all model assumptions [15].

Validation was checked with many replications to ensure the behaviour of distributions that were used. Table 1 shows the validation results. In Table 1, the comparison between observed total time and total simulated time for five different number of replications, including long-term 


\section{SIMULATION MODELLING AND ANALYSIS FOR IMPROVING THE PERFORMANCE OF PRODUCTION} CASE STUDY: JORDANIAN VEHICLES MANUFACTURING COMPANY

Mohammad D. Al-Tahat; Ammar A. Alrousan; Mahmoud Z. Mistarihi; Faten Al Shalabi; Sajeda Abu-Bajah

simulation. As a result, the simulation model of 22 vehicles

was valid and mimic the behaviour of a real system.

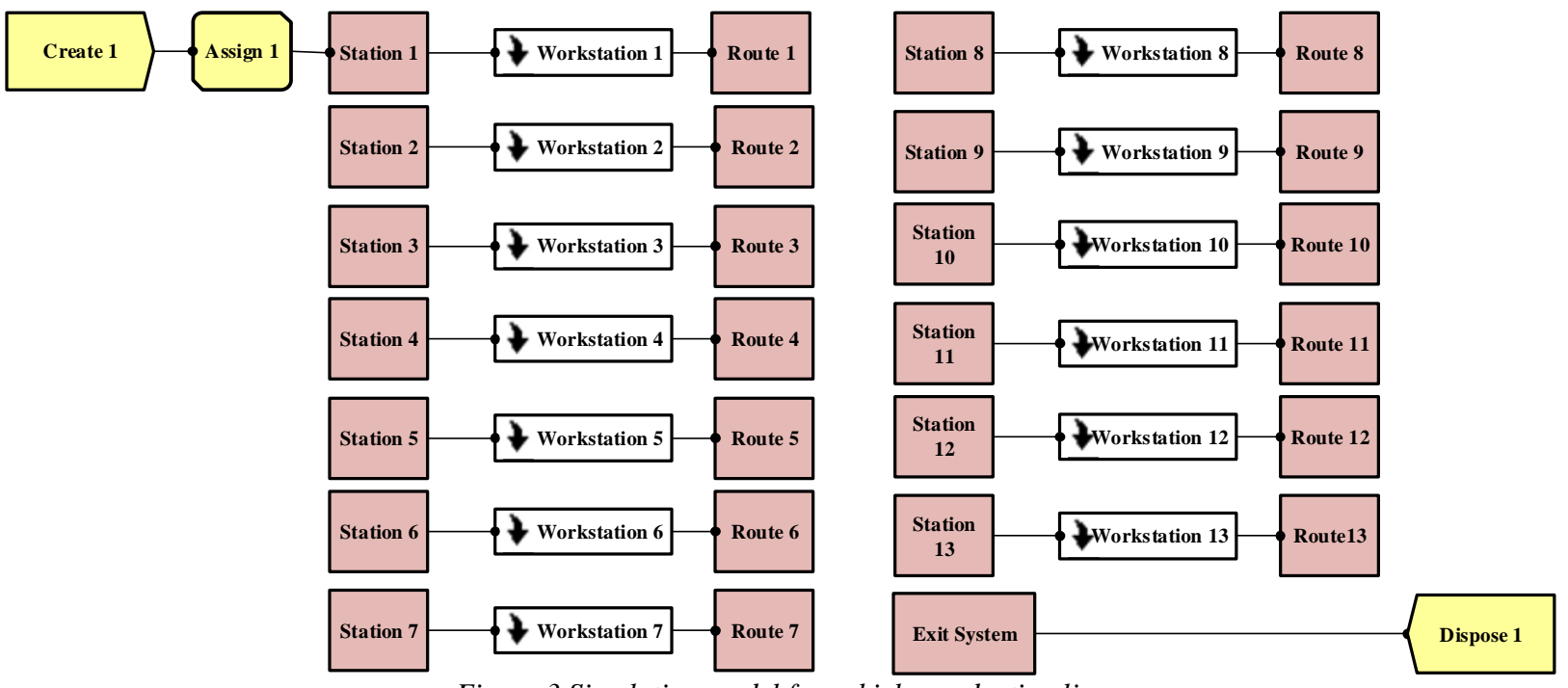

Figure 3 Simulation model for vehicle production line

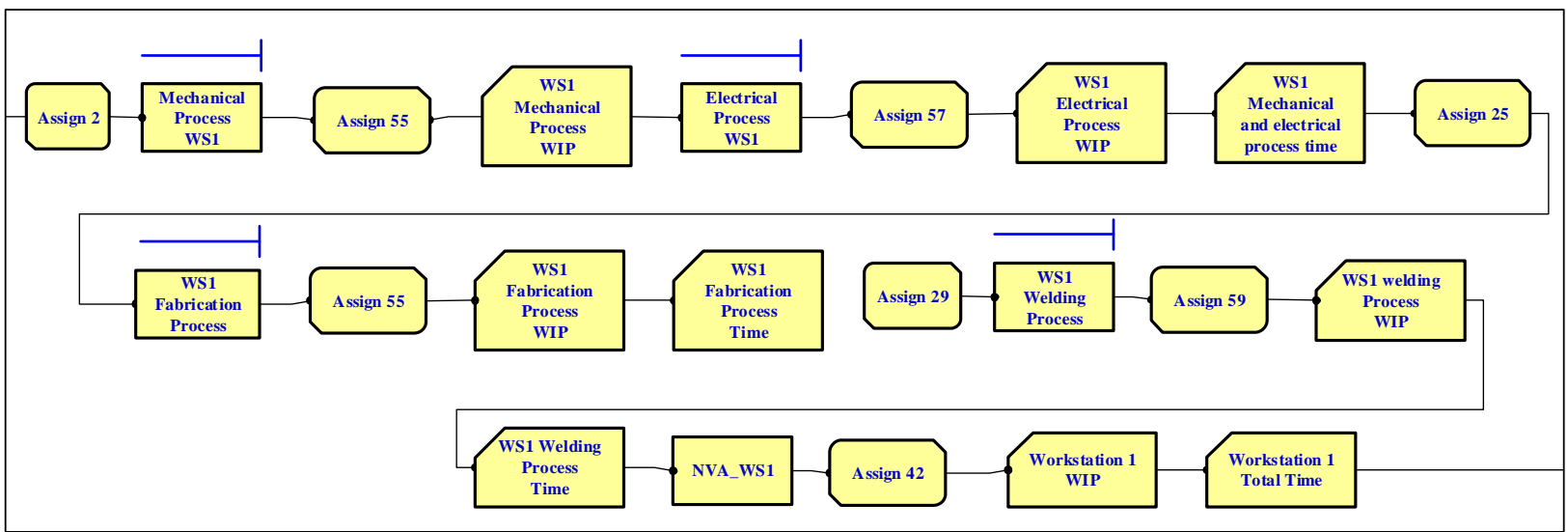

Figure 4 Workstation No. 1 - the current model

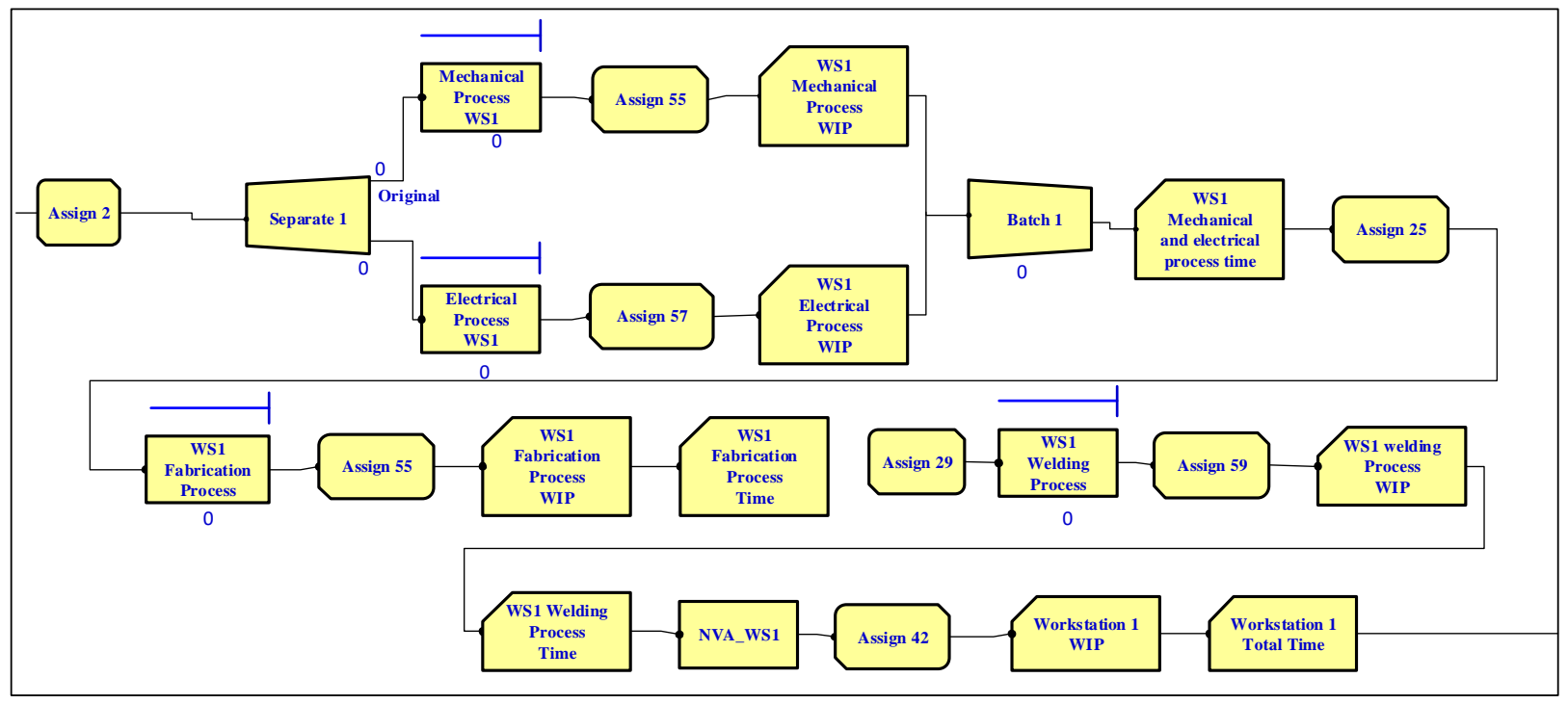

Figure 5 Workstation No. 1 - the proposed model 
SIMULATION MODELLING AND ANALYSIS FOR IMPROVING THE PERFORMANCE OF PRODUCTION CASE STUDY: JORDANIAN VEHICLES MANUFACTURING COMPANY

Mohammad D. Al-Tahat; Ammar A. Alrousan; Mahmoud Z. Mistarihi; Faten Al Shalabi; Sajeda Abu-Bajah

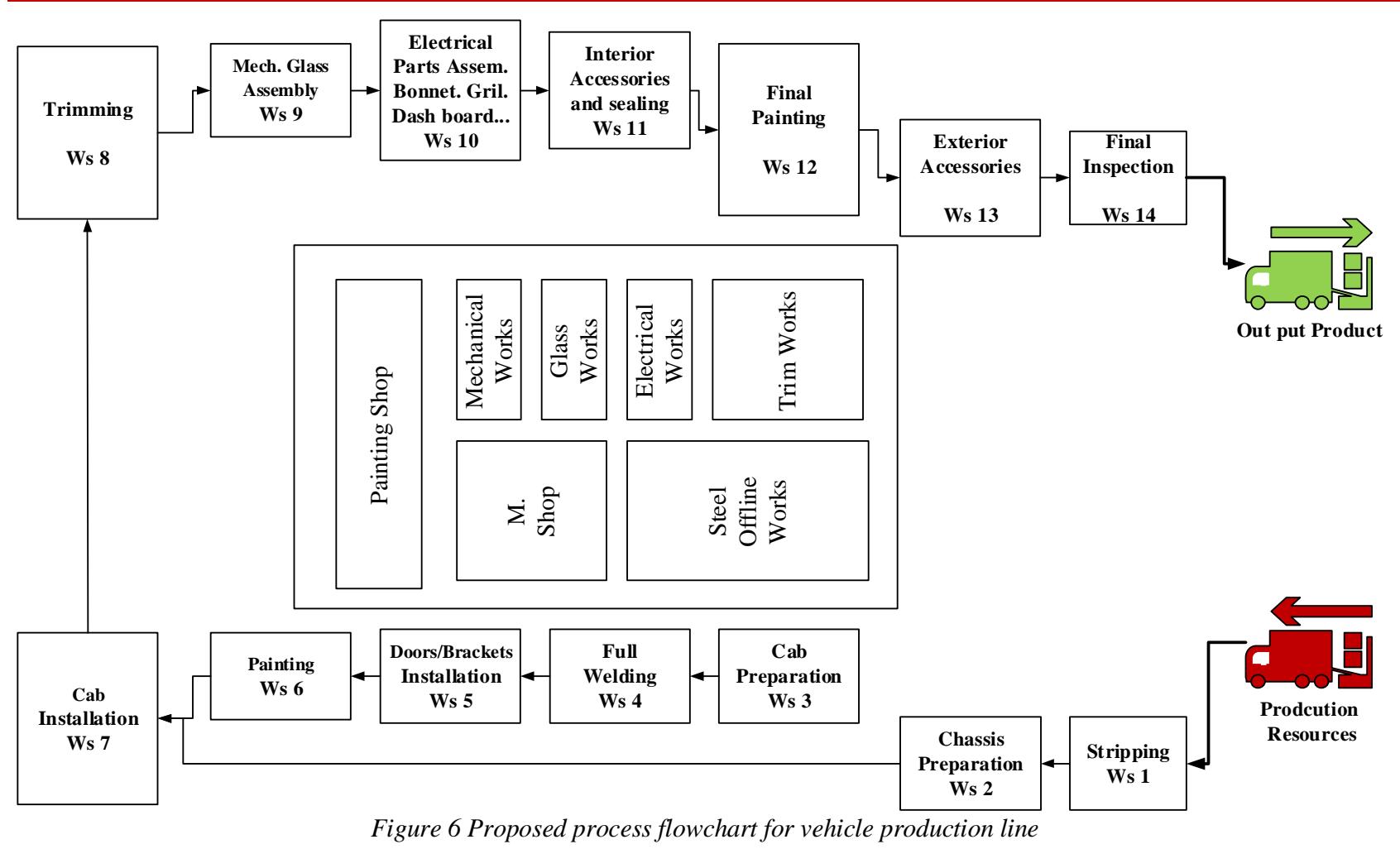

Table 1 Validation Analysis

\begin{tabular}{|c|c|c|c|c|c|}
\hline \multirow{2}{*}{$\begin{array}{c}\text { Total } \\
\text { observed } \\
\text { time }\end{array}$} & \multicolumn{5}{|c|}{$\begin{array}{c}\text { Total simulated time in hours, under } \\
\text { different number of replications }\end{array}$} \\
\cline { 2 - 6 } (Hours) & $\mathrm{R}=1$ & $\mathrm{R}=2$ & $\mathrm{R}=5$ & $\mathrm{R}=10$ & $\mathrm{R}=25$ \\
\hline 456 & 456.39 & 456.40 & 456.42 & 456.53 & 456.50 \\
\hline
\end{tabular}

\section{Results and discussion}

Comparing the status (as-is) of the current follow chart and the current simulation model with (to-be) status, it is found that some processes within the same workstation can be implemented in a parallel manner rather than the current series flow to improve the resources utilisation.

\subsection{Total processing time comparison}

The total accumulated processing time was reduced from (457.3 hours) to (383.0 hours) in the proposed production line layout model. Figure 7 demonstrates how processing time is distributed across all workstations. The WS3 welding process 3 , processes in workstations 4 , and workstations 6 have processing total time higher than the current model.

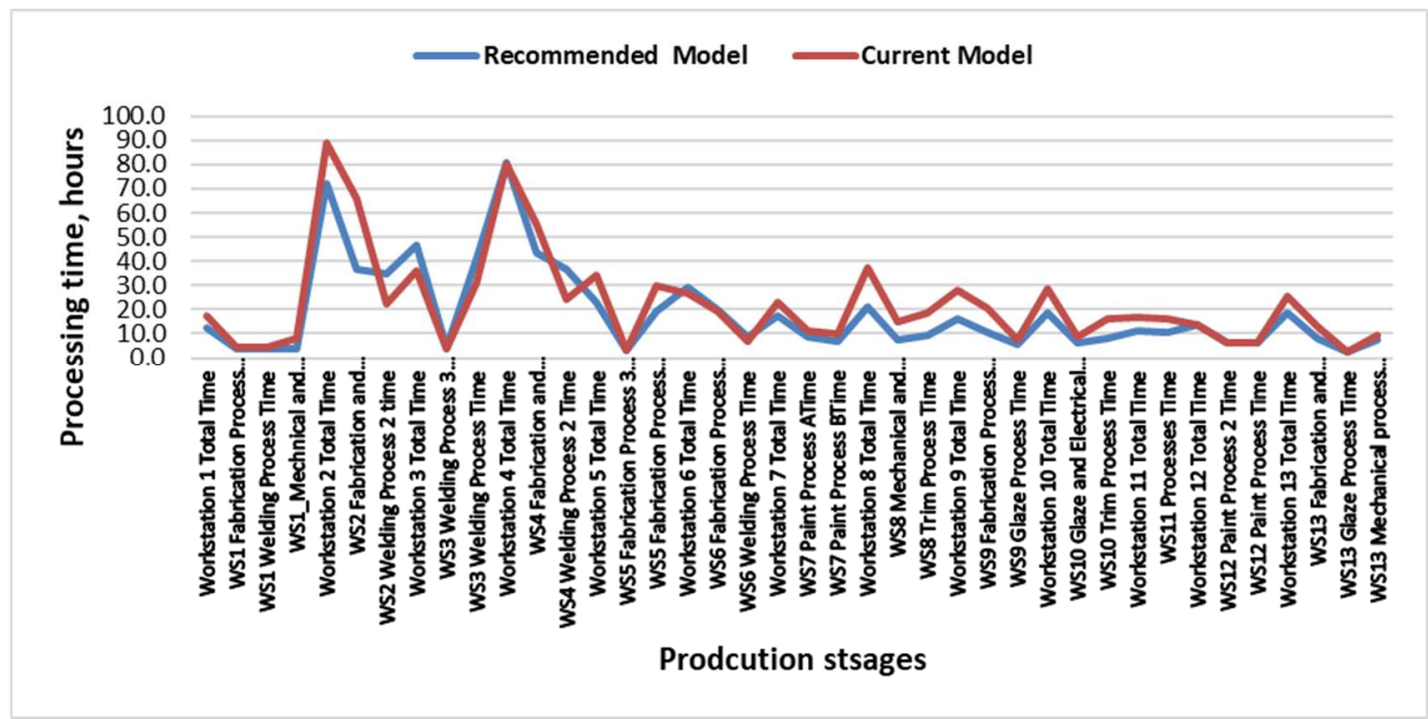

Figure 7 Total processing time comparison between current and recommended model 
SIMULATION MODELLING AND ANALYSIS FOR IMPROVING THE PERFORMANCE OF PRODUCTION CASE STUDY: JORDANIAN VEHICLES MANUFACTURING COMPANY

Mohammad D. Al-Tahat; Ammar A. Alrousan; Mahmoud Z. Mistarihi; Faten Al Shalabi; Sajeda Abu-Bajah

\subsection{Waiting time comparison}

The waiting time comparison between the current model and the proposed model for all queue lines in the $\mathrm{ABC}$ production line, as can be seen from Figure
8 , that 29 out of 47 queue lines have waiting time in the proposed model lower than the current model. At the same time, the remaining queue lines have similar waiting times in both models.

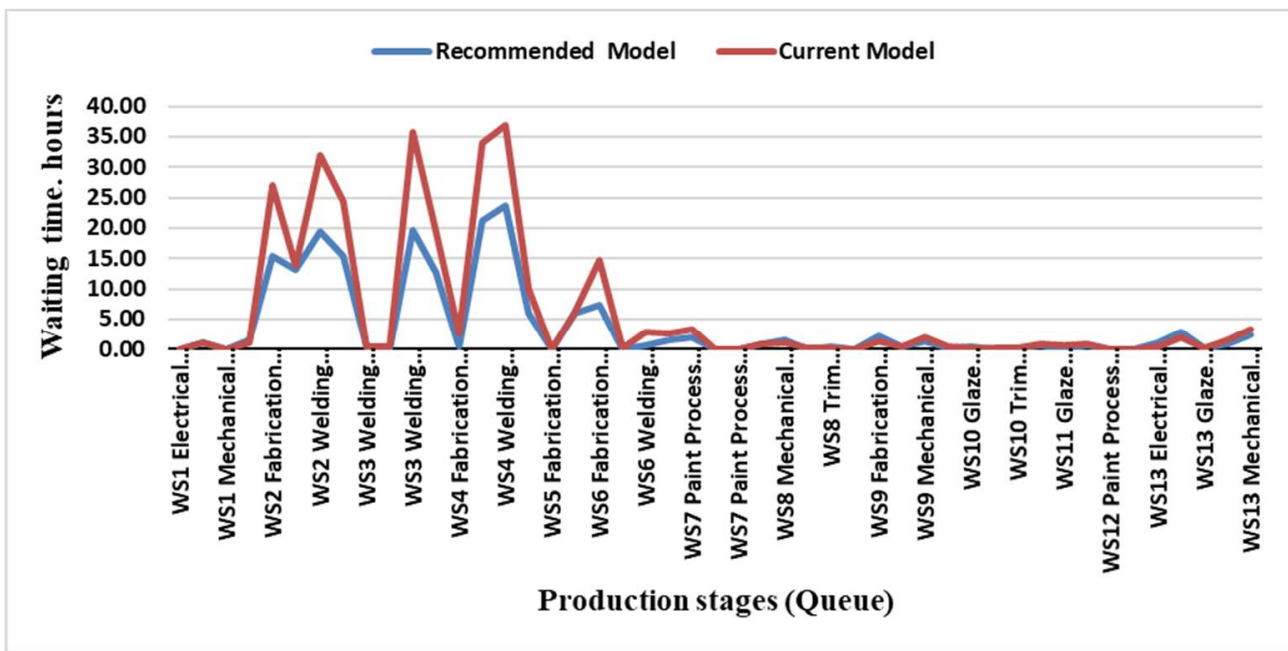

Figure 8 Waiting time comparison between current and recommended model.

\subsection{Comparison of WIP level}

Although, as shown in Figure 9, there are an oscillating discrepancy between the work in process
(WIP) quantity levels in the two models. When the total average (WIP) level for both models is compared, the findings are identical.

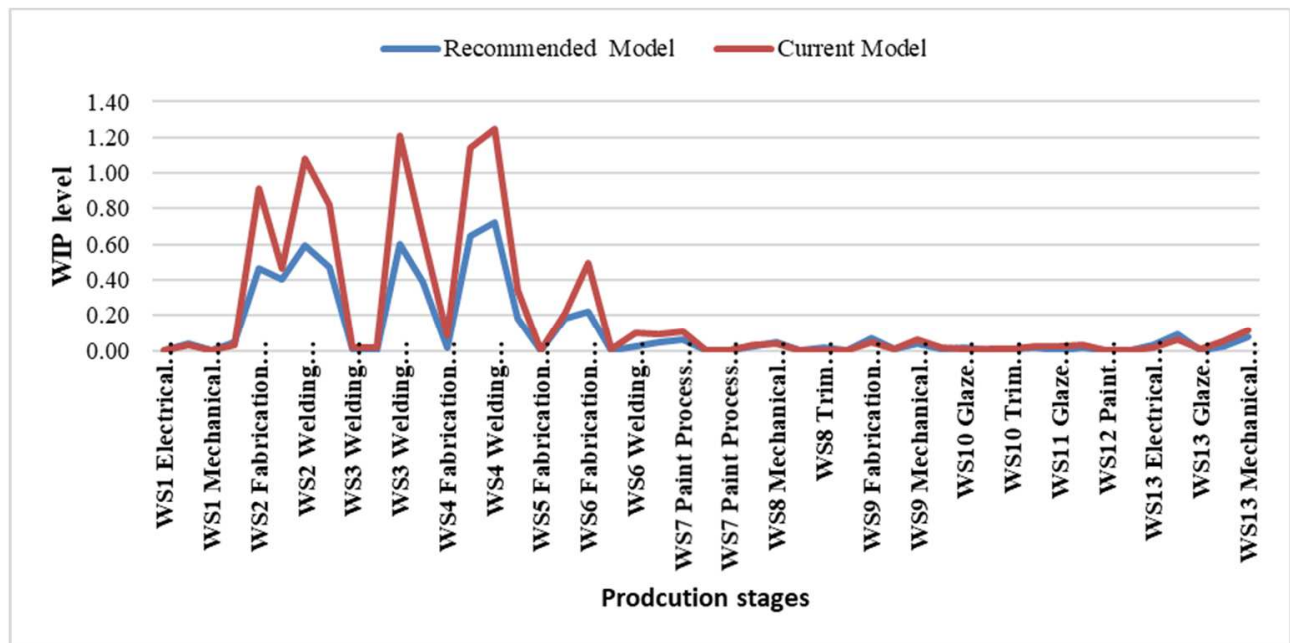

Figure 9 Quantity of WIP comparison between current and recommended model

\subsection{Resource's utilisation}

Figure 10 represents schedule utilisation for resources (workers) in the current model, with schedule utilisation ranging from 9.18 percent to 53.56 percent. Welding worker No. 1 (Weld 1) has the highest schedule utilisation (equals 53.56 percent) followed by fabrication worker No. 19 (Fab 19), which has a value of 45.91 percent. The lowest schedule utilisation for fabrication worker No. 7 (Fab 7) with schedules utilisation is equal to 9.18 percent. 


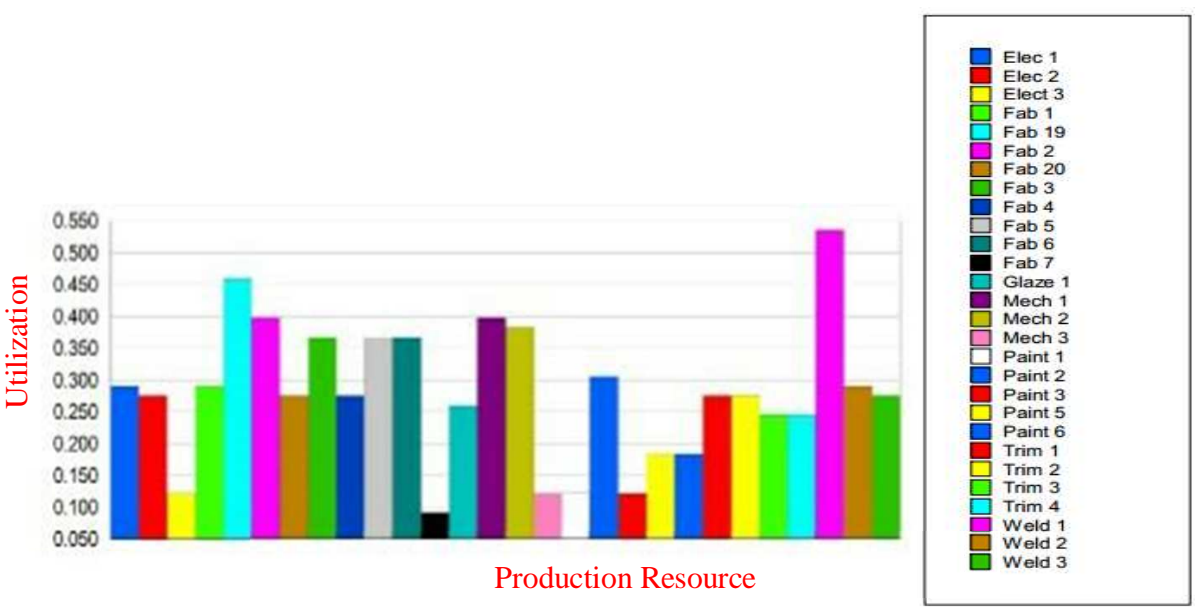

Figure 10 Utilisation of resource - the current model

In the proposed model, the schedule utilisation for resources (workers) ranged between 10.12 percent and 59.02 percent, as shown in Figure 11. Welding worker No. 1 (Weld 1) has the highest utilisation (equals 59.02 percent) followed by fabrication worker
No. 19 (Fab 19), which has a value of 50.59 percent. Whereas the lowest schedule utilisation for fabrication worker No. 7 (Fab 7) with schedules utilisation equal to 10.12 percent.

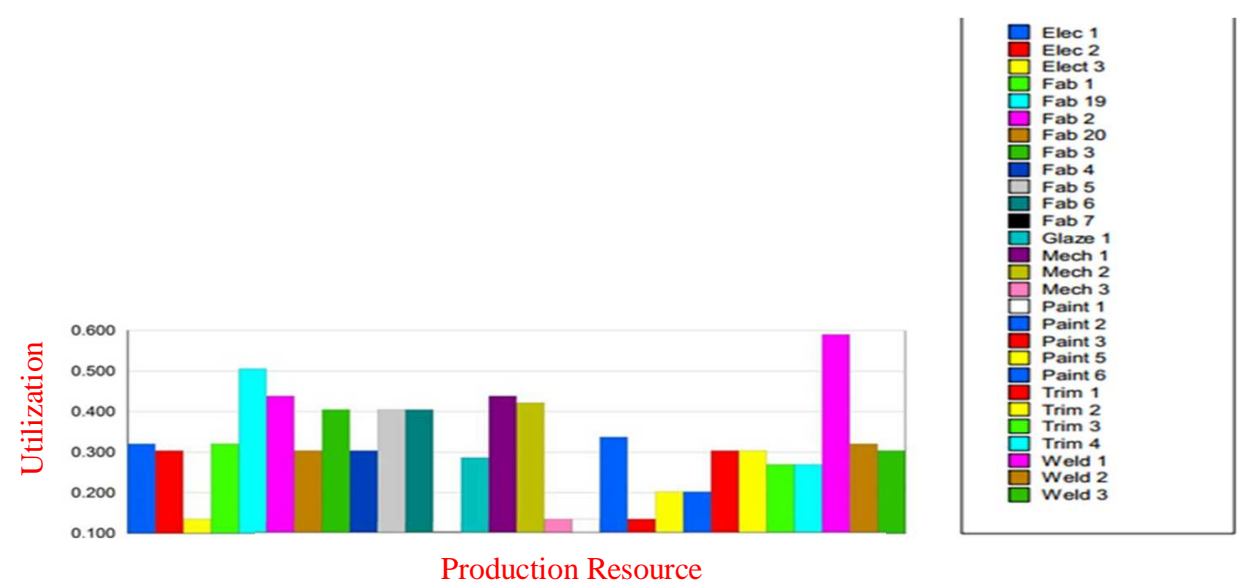

Figure 11 Utilisation of resource - the recommended model

As shown in Table 2, a comparison of schedule utilisation for the proposed model and the current model reveals that overall utilisation for all workers has improved. Fabrication worker No. 7 (Fab 7) improved by 0.94 percent, while welding worker No. 1 improved by 5.46 percent (Weld 1).

\section{Conclusions}

In this paper, a production line of a Jordanian vehicle manufacturing company was efficiently simulated using Arena, to improve and develop a new production line design. Processing time, waiting time, WIP level, and utilisation of capacity have all been used as a performance indicator. After completing this research, verifying, and validating the model and results. Several outcomes were discovered, including the following.
- According to the results, the proposed simulation model has achieved a significant reduction in both total and waiting times. It is also shown that the proposed model has a slightly lower WIP level than the current model.

- Moreover, the overall resource utilisation in the proposed model is better than the current model by approximately $10.21 \%$.

- By following the simulation methodology presented in this paper, general production lines can be analysed, regardless of size, used technology, variation, or the multiplicity of their products, by following the simulation methodology presented in this paper, not only that but also systems production services can be analysed in the same manner, implying that the simulation system presented here can be used in the analysis of all 
SIMULATION MODELLING AND ANALYSIS FOR IMPROVING THE PERFORMANCE OF PRODUCTION CASE STUDY: JORDANIAN VEHICLES MANUFACTURING COMPANY

Mohammad D. Al-Tahat; Ammar A. Alrousan; Mahmoud Z. Mistarihi; Faten Al Shalabi; Sajeda Abu-Bajah

production lines, whether it is configured in a serial, parallel or hybrid structure.

Table 2 Schedule Utilization Comparison

\begin{tabular}{|l|c|c|c|c|}
\hline \multirow{2}{*}{$\begin{array}{c}\text { Resource } \\
\text { Name }\end{array}$} & \multicolumn{2}{|c|}{ Utilisation (\%) } & \multicolumn{2}{c|}{ Improvement } \\
\cline { 2 - 5 } & Proposed & Current & $\begin{array}{c}\text { Amount } \\
(\%)\end{array}$ & Rate $(\%)$ \\
\hline Elec 1 & 32.04 & 29.07 & 2.97 & 10.22 \\
\hline Elec 2 & 30.35 & 27.54 & 2.81 & 10.20 \\
\hline Elec 3 & 13.49 & 12.24 & 1.25 & 10.21 \\
\hline Fab 1 & 32.04 & 29.07 & 2.97 & 10.22 \\
\hline Fab 19 & 50.59 & 45.91 & 4.68 & 10.19 \\
\hline Fab 2 & 43.84 & 39.78 & 4.06 & 10.21 \\
\hline Fab 20 & 30.35 & 27.54 & 2.81 & 10.20 \\
\hline Fab 3 & 40.47 & 36.72 & 3.75 & 10.21 \\
\hline Fab 4 & 30.35 & 27.54 & 2.81 & 10.20 \\
\hline Fab 5 & 40.47 & 36.72 & 3.75 & 10.21 \\
\hline Fab 6 & 40.47 & 36.72 & 3.75 & 10.21 \\
\hline Fab 7 & 10.12 & 9.18 & 0.94 & 10.24 \\
\hline Glaze 1 & 28.67 & 26.01 & 2.66 & 10.23 \\
\hline Mech 1 & 43.84 & 39.78 & 4.06 & 10.21 \\
\hline Mech 2 & 42.16 & 38.25 & 3.91 & 10.22 \\
\hline Mech 3 & 13.49 & 12.24 & 1.25 & 10.21 \\
\hline Paint 1 & 13.49 & 12.24 & 1.25 & 10.21 \\
\hline Paint 2 & 33.73 & 30.60 & 3.13 & 10.23 \\
\hline Paint 3 & 13.49 & 12.24 & 1.25 & 10.21 \\
\hline Paint 5 & 20.24 & 18.36 & 1.88 & 10.24 \\
\hline Paint 6 & 20.24 & 18.36 & 1.88 & 10.24 \\
\hline Trim 1 & 30.35 & 27.54 & 2.81 & 10.20 \\
\hline Trim 2 & 30.35 & 27.54 & 2.81 & 10.20 \\
\hline Trim 3 & 26.98 & 24.48 & 2.5 & 10.21 \\
\hline Trim 4 & 26.98 & 24.48 & 2.5 & 10.21 \\
\hline Weld 1 & 59.02 & 53.56 & 5.46 & 10.19 \\
\hline Weld 2 & 32.04 & 29.07 & 2.97 & 10.22 \\
\hline Weld 3 & 30.35 & 27.54 & 2.81 & 10.20 \\
\hline Average & 30.71 & 27.87 & 2.85 & 10.21 \\
\hline Average & 383 hour & 457.3 & $-74.3^{*}$ & $-16.25^{*}$ \\
\hline Average & 183.16 & 284.5 & $-101.34^{*}$ & $-35.62^{*}$ \\
\hline Average & 19.9 & 21.7 & $-1.8 *$ & $-8.29^{*}$ \\
\hline & & & & \\
& & & & \\
\hline
\end{tabular}

\section{References}

[1] JERRY, B., JOHN, S. C., BARRY, L., N.: Discreteevent system simulation, $2^{\text {nd }}$ ed., Upper Saddle River, N.J.: Prentice-Hall, 1999.

[2] HOSSEINPOUR, F., HAJIHOSSEINI, H.: Importance of simulation in manufacturing, World Academy of Science, Engineering and Technology, Vol. 51, pp. 285-288, March 2009.

[3] ANTHONY, F., EUGENE, B., DENNIS, K., STEPHEN, H., DAN, L., JAMESON, J., JOSEPH, L.: Harrison's Principles of Internal Medicine, $17^{\text {th }}$ ed., New York, NY. McGraw-Hill, 2008.

[4] HASSEN, M. B., TURKI, M., GARGOURI, F.: 'A proposal to model knowledge dimension in sensitive business processes', International Conference on Intelligent Systems Design and Applications, Springer, Cham, pp. 1015-1030, 2016.
[5] PATALAS-MALISZEWSKA, J., KREBS, I.: 'Decision model for the use of the application for knowledge transfer support in manufacturing enterprises', In: Abramowicz W. (eds) Business Information Systems Workshops. BIS 2015. Lecture Notes in Business Information Processing, vol 228. Springer, Cham. doi:10.1007/978-3-319-26762-3_5

[6] KIM, S., HWANG, H., SUH, E.: A process-based approach to knowledge-flow analysis: a case study of a manufacturing firm, Knowledge and Process Management, Vol. 10, No. 4, pp. 260-276, 2003.

[7] PATALAS-MALISZEWSKA, J., AND KREBS, I.: 'An information system supporting the Eliciting of expert knowledge for successful IT projects, In: Damaševičius R., Vasiljevienè G. (eds) Information and Software Technologies. ICIST 2018, Communications in Computer and Information Science, Vol. 920, Springer, Cham. doi:10.1007/978-3-319-99972-2_1

[8] HAN, J., LEE, S. H., KIM, J. K.: A process integrated engineering knowledge acquisition and management model for project-based manufacturing, International Journal of Precision Engineering and Manufacturing, Vol. 18, No. 2, pp. 175-185, 2017.

[9] PAPADOPOULOS D., O' KELLY H.T., VIDALIS M., E. J., SPINELLIS J.: Analysis and Design of Discrete Part Production Lines, Springer Science, 2009. doi:10.1007/978-0-387-89494-2_6

[10] PEKARČÍKOVÁ, M., TREBUŇA, P., MARKOVIČ, J.: Simulation as part of industrial practice, Acta logistica, Vol. 2, No. 2, pp. 5-8, 2015. doi:10.22306/al.v2i2.36

[11] SERAJ, Y.A.: A simulation study to increase the capacity of a rusk production line, International Journal of Mathematics and Computers in Simulation, Vol. 2, No. 3, pp. 228-237, 2008.

[12] LAW, A.: Simulation Modelling and Analysis, $4^{\text {th }}$ ed., New York, McGraw-Hill, 2007.

[13] CHUNG C.A.; Simulation Modelling Handbook: A Practical Approach, CRC Press, 2019.

[14] MIRZAPOURREZAEI, S., LALMAZLOUMIAN, M., DARGI, A., WONG, K.: 'Simulation of a Manufacturing Assembly Line Based on Witness', 2011 Third International Conference on Computational Intelligence, Communication Systems and Networks, 2011, pp. 132-137, doi:10.1109/CICSyN.2011.38

[15] DREVNA, M., KASALES, C.: 'Introduction to Arena', Proceedings of the $26^{\text {th }}$ conference on Winter simulation, WSC 1994, Lake Buena Vista, FL, USA, December 11-14, 1994.

\section{Review process}

Single-blind peer review process. 